\title{
Fast Switching of Vertically Aligned Liquid Crystals by Low-Temperature Curing of the Polymer Structure
}

\author{
Byung Wok Park, Seung-Won Oh, Jung-Wook Kim, and Tae-Hoon Yoon* \\ Department of Electronics Engineering, Pusan National University, Busan 609-735, Korea
}

(Received June 13, 2014 : revised July 15, 2014 : accepted August 1, 2014)

\begin{abstract}
We proposed a method for fast turn-off switching of a vertically-aligned liquid crystal cell by low-temperature curing of the polymer structure. We confirmed that the turn-off times of the fabricated cells were reduced significantly as the curing temperature was lowered to $-20^{\circ} \mathrm{C}$. We accounted for the effect of low-temperature curing on the turn-off time by using a mathematical model and by observing images obtained via scanning electron microscopy. We also confirmed that low-temperature curing is more effective in reducing the response time when the device is operated at a low temperature.
\end{abstract}

Keywords: Liquid crystal, Vertical alignment, Curing temperature, Response time

OCIS codes : (160.3710) Liquid crystals; (120.0120) Instrumentation, measurement, and metrology; (120.2040) Displays

\section{INTRODUCTION}

Recently there has been a rapidly increasing demand for liquid-crystal displays (LCDs) because of their low price, low power consumption, light weight, low thickness, and high resolution. However, their response time is slower than that of other display devices because their switching speed is limited by the material parameters of the liquid crystal (LC) molecules. Although the turn-on time can be reduced by employing an overdriving scheme $[1,2]$, it is not easy to reduce the turn-off time because it is limited by the slow relaxation of the LCs. Slow response results in motion blur and tailing in displayed images. In particular, fast switching of LCs is considered to be a very important factor in a three-dimensional display device because slow switching of the LC molecules is the main cause of crosstalk between the left and right eye images $[3,4]$. Moreover, LCDs show poor performance when operated at a low temperature because the response time of the LCs increases drastically, owing to the increase in the rotational viscosity as the temperature decreases [5]. This can cause a severe problem when LCDs are used in outdoor environments during winter in applications such as cellular phones, tablet PCs, and car navigation systems.

The twisted-nematic, vertical alignment (VA), and in-plane switching modes have been widely used for applications in smart phones, tablet PCs, monitors, and TVs [6-8]. Among the various LCD modes, the VA mode exhibits a superior dark state because the LC molecules are aligned perpendicular to the substrate in the initial dark state, resulting in a high contrast ratio $[9,10]$. However, the response time of the VA mode is not sufficiently fast to realize high-quality video $[11,12]$. To reduce the response time several methods have been proposed [13-24], but they have drawbacks, such as a complicated driving scheme, complex fabrication process, and increase in the operating voltage. Moreover, there have been only a few studies of the fast switching of LCs at low temperature.

In this work we demonstrate that the response time of a VA cell can be reduced by forming polymer networks at a low temperature. We found that the turn-off time of the polymer-networked LC cell is reduced as the curing temperature is lowered. We also confirmed that low-temperature curing of the polymer structure is more effective for reducing the response time at a low temperature.

\section{CELL FABRICATION}

We fabricated a polymer-networked VA cell to confirm

\footnotetext{
*Corresponding author: thyoon@pusan.ac.kr

Color versions of one or more of the figures in this paper are available online.
} 
the effect of the curing temperature on the response time. We used a nematic LC with negative dielectric anisotropy of -2.7 and optical anisotropy of 0.102 as the host LC. The rotational viscosity of the host LC is $106 \mathrm{mPa} \mathrm{s}$. First, a reactive mesogen (RM) was mixed with the host LC molecules. RMS 03-015 (Merck) was employed as the liquid crystalline prepolymer, which can be used to fabricate a phase retarder working as a $+\mathrm{C}$ plate. We prepared LC mixtures with RM concentrations of $0.2,1.0$, and $3.0 \mathrm{wt} \%$; these mixtures were stirred for 24 hours by a magnetic stirrer. An ultrasonic wave was applied to the mixtures for $30 \mathrm{~min}$. For homeotropic alignment of LCs, polyimide was coated onto ITO glass substrates using the spin-coating technique. The coated substrates were prebaked at $80^{\circ} \mathrm{C}$ for $3 \mathrm{~min}$ and then hard-baked at $230^{\circ} \mathrm{C}$ for 20 min. The cell thickness was maintained at $3.2 \mu \mathrm{m}$ by ball-type spacers. The LC mixture was injected into the cell via capillary action and UV light with an intensity of $20 \mathrm{~mW} / \mathrm{cm}^{2}$ was then used to irradiate the cell for $100 \mathrm{~s}$, to form polymer networks in the bulk region at three different curing temperatures of $60^{\circ} \mathrm{C}, 20^{\circ} \mathrm{C}$, and $-20^{\circ} \mathrm{C}$.

\section{EXPERIMENTAL RESULTS AND DISCUSSION}

To investigate the effect of low-temperature curing of the polymer structure, voltage-transmittance (V-T) curves were measured as the amplitude of a $1-\mathrm{kHz}$ square voltage pulse was varied. Figure 1 shows the V-T curves for the VA cells fabricated by forming polymer networks at room temperature. The maximum transmittance of a VA cell with pure LC was $33 \%$. As the concentration of the RM was increased, the operating voltage increased and the transmittance decreased [17, 18]. VA cells polymer-networked with RM concentrations of $0.2,1$, and $3 \mathrm{wt} \%$ showed maximum transmittances of $32.5 \%, 29.8 \%$, and $27.7 \%$ respectively.

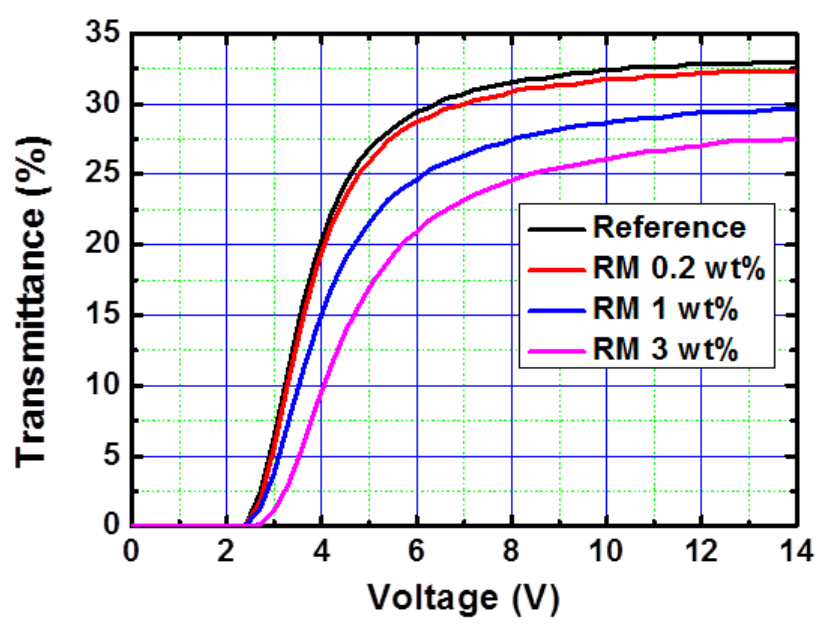

FIG. 1. Measured V-T curves of the VA cells fabricated by curing the polymer networks at room temperature.
Figure 2 shows the measured response times of the fabricated cells. The turn-on time is defined as the transient time from $10 \%$ to $90 \%$ of the maximum transmittance, and vice versa for the turn-off time. A VA cell with pure $\mathrm{LC}$ at room temperature shows turn-on and turn-off times of 21.3 and $6.8 \mathrm{~ms}$ respectively. When the concentration of the RM was $0.2,1$, and $3 \mathrm{wt} \%$, the turn-on time was 9.0, 8.7, and $4.7 \mathrm{~ms}$, and the turn-off time was $6.1,5.5$, and $4.1 \mathrm{~ms}$ at room temperature, respectively.

As expected, the total response times were reduced by the formation of the polymer structure [18]. As the concentration of RM in the initial LC/prepolymer mixture was increased, the density of the polymer network in the VA cell increased as well. Accordingly, the number of anchoring boundaries increased and the total force of restitution owing to the anchoring effect of the RM molecules increased as well, resulting in faster turn-off times. The optical bouncing in the fabricated VA cells can be reduced by the polymer networks formed, so that a higher driving

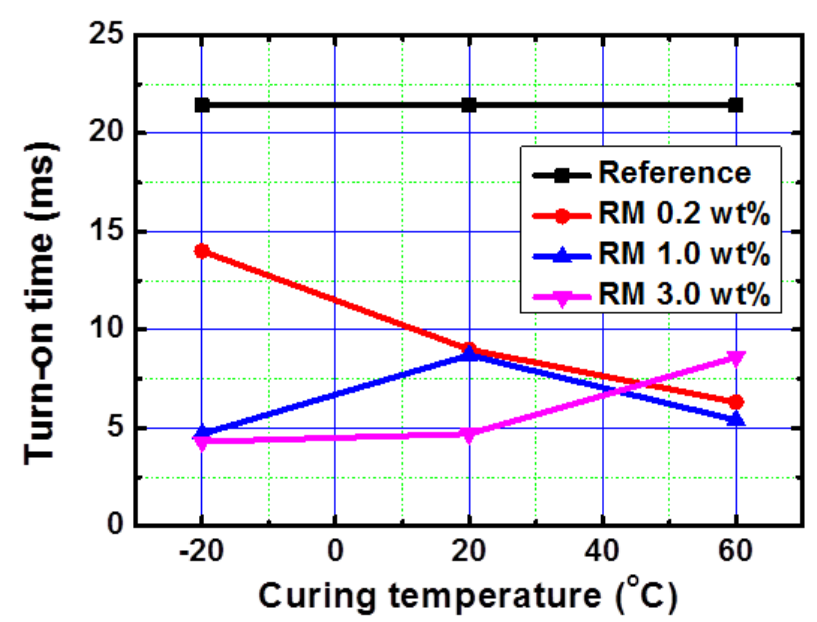

(a)

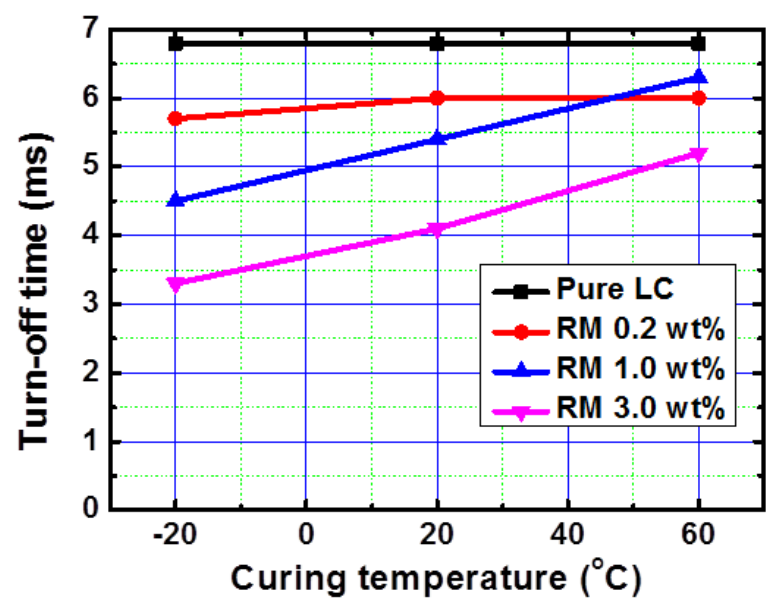

(b)

FIG. 2. (a) Turn-on and (b) turn-off times of the VA cells polymer-networked with various RM concentrations, as functions of the curing temperature. 
voltage can be applied to polymer-networked VA cells, resulting in a faster turn-on time [18].

To investigate the influence of the curing temperature on the response time, we measured the electro-optical characteristics of the VA cells polymer-networked at the three different curing temperatures of $60^{\circ} \mathrm{C}, 20^{\circ} \mathrm{C}$, and $-20^{\circ} \mathrm{C}$, as shown in Fig. 2. There is little influence of the curing temperature on the turn-on time. On the other hand, the turn-off time decreased significantly as the curing temperature was decreased: When curing was performed at room temperature, the turn-off time of the VA cells with an RM concentration of $3 \mathrm{wt} \%$ was reduced by $38 \%$. When the curing temperature was decreased to $-20^{\circ} \mathrm{C}$, the turn-off time of the VA cells was reduced by $54 \%$. On the other hand, when the curing temperature was increased to $60^{\circ} \mathrm{C}$ the turn-off time was reduced only by $24 \%$. Thus we confirm that the turn-off time of the fabricated cells can be reduced significantly as the curing temperature is decreased.

To investigate the reason for the reduction in turn-off time with decreasing curing temperature, we observed the polymer network structure formed in the VA cells using scanning electron microscopy (SEM). The fabricated cells were placed in isopropyl alcohol for more than 24 hours to remove the LCs while the polymer structure was maintained. Figure 3 shows the SEM images of the cross

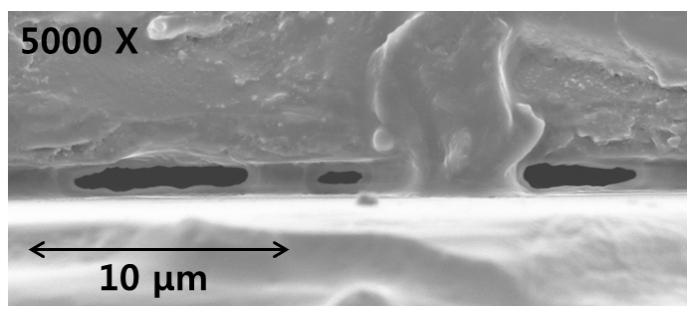

(a)

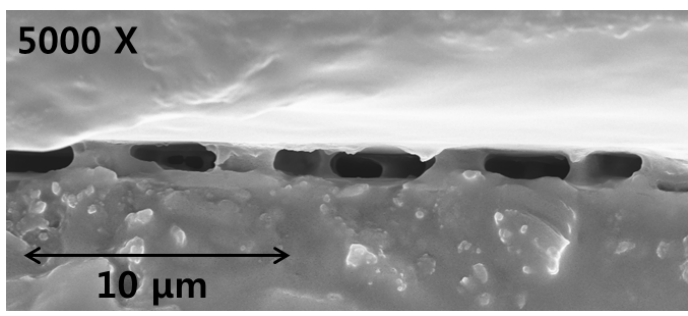

(b)

\section{$5000 X$}

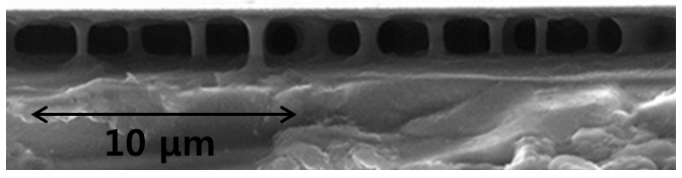

(c)

FIG. 3. SEM images of the cross section of the VA cells polymer-networked at temperatures of (a) $60^{\circ} \mathrm{C}$, (b) $20^{\circ} \mathrm{C}$, and (c) $-20^{\circ} \mathrm{C}$. section of the VA cells with an RM concentration of 3 $\mathrm{wt} \%$ as the curing temperature is varied. When the curing temperature was $60^{\circ} \mathrm{C}$ the cross-sectional SEM image showed that the domains formed by the polymer bundle structure were rather nonuniform, and the domain size and radius of the polymer bundles were rather large. When the curing temperature was $20^{\circ} \mathrm{C}$ the polymer structure in the cell was more uniform than that cured at $60^{\circ} \mathrm{C}$ and the radius of the polymer bundles was smaller. When the curing temperature was lowered farther to $-20^{\circ} \mathrm{C}$ the distance between the polymer structures was more uniform than after curing at $20^{\circ} \mathrm{C}$, and the size of the domains and the radius of the polymer bundles were even smaller. We infer that the turn-off time of a polymer-networked VA cell is dependent on the uniformity, domain size, and bundle radius of the polymer structure formed.

As the curing temperature climbs, the diffusion process of the monomers becomes faster and more polymers can get together to form larger bundles during the phase separation [25]. This tendency was confirmed by the SEM images shown in Fig. 3. The polymer network is coarser at higher curing temperature, resulting in weaker interaction between LC molecules and polymers. Therefore the turnoff time of the fabricated cell slows as the curing temperature rises. On the other hand, lower curing temperature yields polymer networks with smaller bundle size, which allows a faster turn-off time. This follows from the dynamics of the LC molecules in a polymer-stabilized cell being strongly dominated by the polymer structure.

Recently Deng-Ke Yang's group developed a simple phenomenological model to estimate the threshold voltage and turn-off time of a polymer-stabilized LC cell [26]. They derived formulas by introducing the effective aligning field of the polymer network, which can be used to investigate the effect of polymer networks on LC molecules. We compared our experimental results for threshold voltage and turn-off time to results calculated using the formulas. The formula for the threshold voltage is

$$
V_{c} \approx V_{0}\left(1+\frac{c(h / R)^{2}}{2 \pi}\right)^{1 / 2}
$$

where $V_{0}$ is the threshold voltage of the pure liquid crystal, $c$ is the fraction of polymer network, $h$ is the cell thickness, and $R$ is the radius of the polymer bundles. According to this formula, the threshold voltage increases with increasing polymer volume fraction. For a fixed polymer fraction the threshold voltage gets higher as the radius of the polymer bundles gets smaller, because the distance between the polymer bundles gets shorter. The formula for the turn-off time is

$$
\tau \approx \frac{\tau_{0}}{1+c(h / R)^{2} / 2 \pi}
$$


where $\tau_{0}$ is the turn-off time of the pure liquid crystal. The turn-off time decreases with increasing polymer volume fraction. For a fixed polymer fraction the turn-off time gets smaller as the radius of the polymer bundles gets smaller, because of the shorter distance between the polymer bundles. Figure 4(a) shows the dependence of the threshold voltage on the curing temperature for cells with $\mathrm{RM}$ concentration of $3 \mathrm{wt} \%$. We substitute the threshold voltage value into Eq. (1) to extract the value of $R$ from the formula, and then we substitute this $R$ value into Eq. (2) to calculate the turn-off time. Figure 4(b) shows the measured turn-off times of the fabricated cells and the turn-off times calculated using Eqs. (1) and (2). We can confirm that the calculated and experimental results show the same trend: the turn-off time decreased as the curing temperature was decreased. However, there are discrepancies between the calculated results and experimental results, which are probably due to the assumptions of periodicity

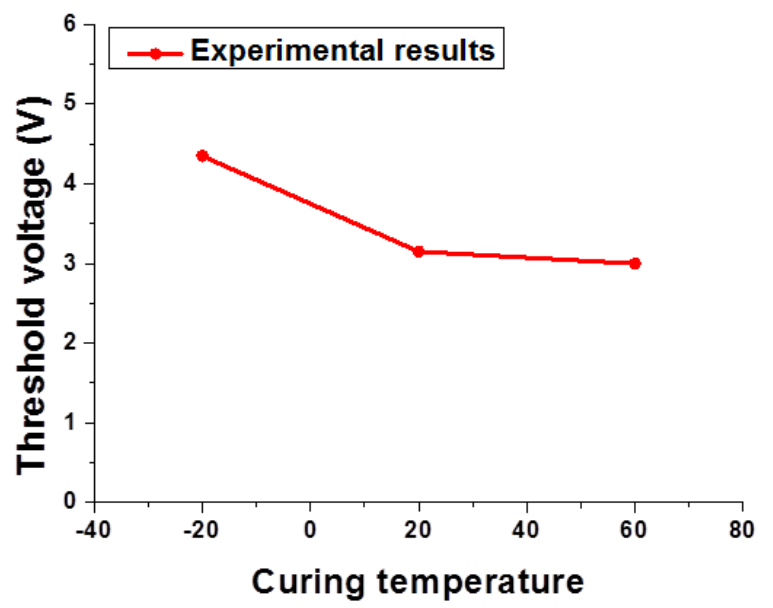

(a)

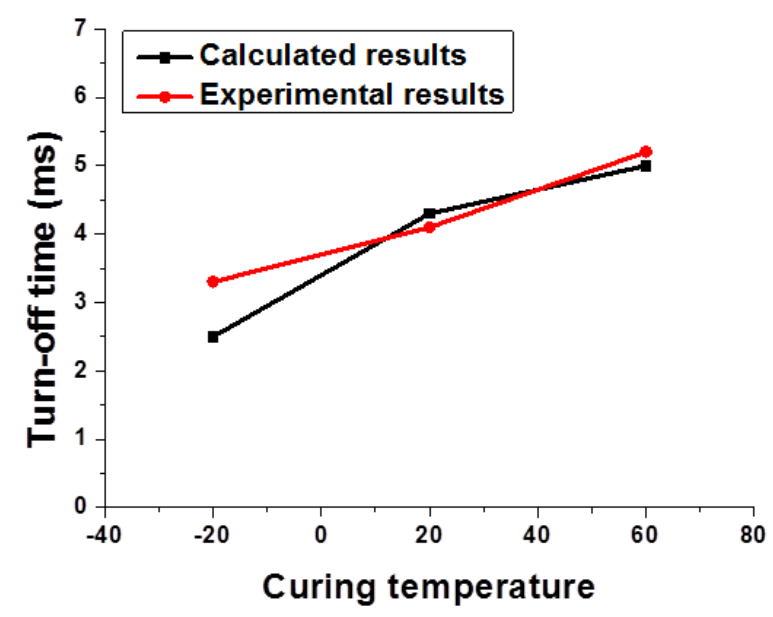

(b)

FIG. 4. (a) Threshold voltages and (b) measured and calculated turn-off times of the VA cells polymer-networked with an RM concentration of $3.0 \mathrm{wt} \%$, as functions of the curing temperature. and uniformity in the polymer network.

To investigate the operation-temperature-dependent effect of the low-temperature curing, we measured the response times of the fabricated cells as the temperature of device operation was varied, as shown in Fig. 5. The transmittances of LC cells with crossed polarizers were measured using a white-light source with emission wavelengths ranging from 380 to $780 \mathrm{~nm}$. The temperature of the LC cells was controlled using a hot and cold stage system (HCS204V -mk1000, Instec Inc.) with a resolution of $0.01^{\circ} \mathrm{C}$. The hot

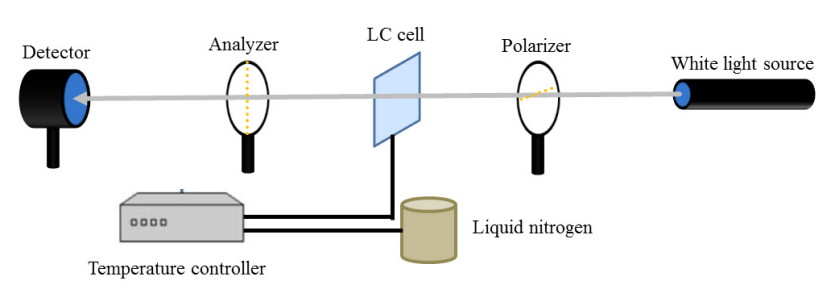

FIG. 5. Experimental setup for the low-temperature measurement.

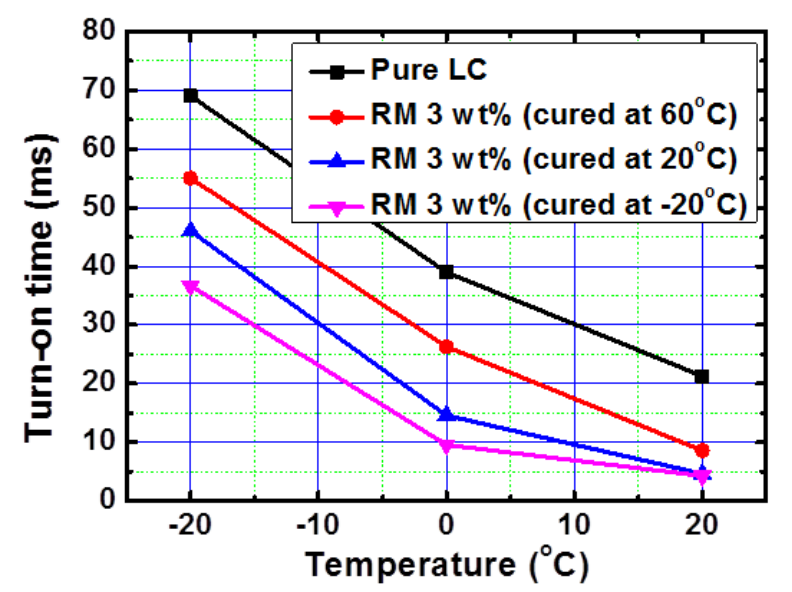

(a)

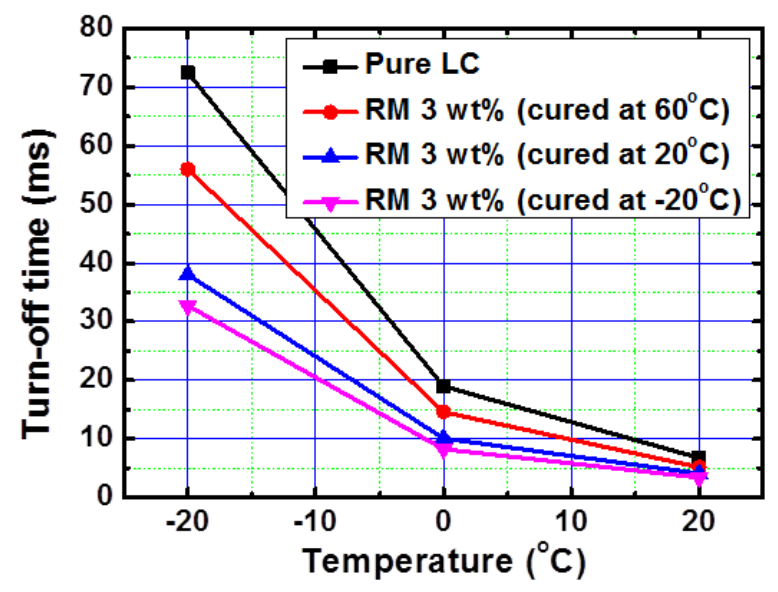

(b)

FIG. 6. (a) Turn-on and (b) turn-off times of the VA cells polymer-networked with an RM concentration of $3 \mathrm{wt} \%$, as functions of the operating temperature. 
and cold stage system can decrease the temperature of a sample cell to $-60^{\circ} \mathrm{C}$ by using a liquid-nitrogen cooling system. The transmittance and response time were measured in the presence of an applied electric field. We measured the turn-on and turn-off times of the fabricated cells at temperatures ranging from $-20^{\circ} \mathrm{C}$ to $20^{\circ} \mathrm{C}$, as shown in Fig. 6 . The RM mixing ratio was maintained at $3 \mathrm{wt} \%$, for which the fastest response of the LCs can be observed. Both the turn-on and turn-off times decreased as the curing temperature was lowered to $-20^{\circ} \mathrm{C}$. However, when the operating temperature was lowered to $-20^{\circ} \mathrm{C}$, the improvement ratio of the turn-on time decreased, while the improvement ratio of the turn-off time increased as the operating temperature of the device was lowered to $-20^{\circ} \mathrm{C}$. When the device was operated at $20^{\circ} \mathrm{C}$ the turn-off time of the cell cured at $-20^{\circ} \mathrm{C}$ was reduced by $54 \%$; when it was operated at $0^{\circ} \mathrm{C}$ its turn-off time was reduced by $57 \%$, and when it was operated at $-20{ }^{\circ} \mathrm{C}$ its turn-off time was reduced by $60 \%$. We see that the improvement ratio of the turn-off time of the cell cured at $-20^{\circ} \mathrm{C}$ increased as the operating temperature of the device was lowered, so we can confirm that lowtemperature curing of the polymer structure is more effective for reducing the response time when the device is operated at low temperature.

Although the fabricated cell could provide a fast response when the polymer was cured at a low temperature, the maximum transmittance decreased and the operating voltage increased as the curing temperature was lowered, as shown in Fig. 7. The polymer structure confines a small amount of LCs inside the polymer pillars, and the shape and size of the domains formed by the polymer structure affect the motion of the LC molecules in a domain. We expect that optimization of the experimental conditions could minimize the decrease in transmittance while maintaining the fast response due to curing at a low temperature.

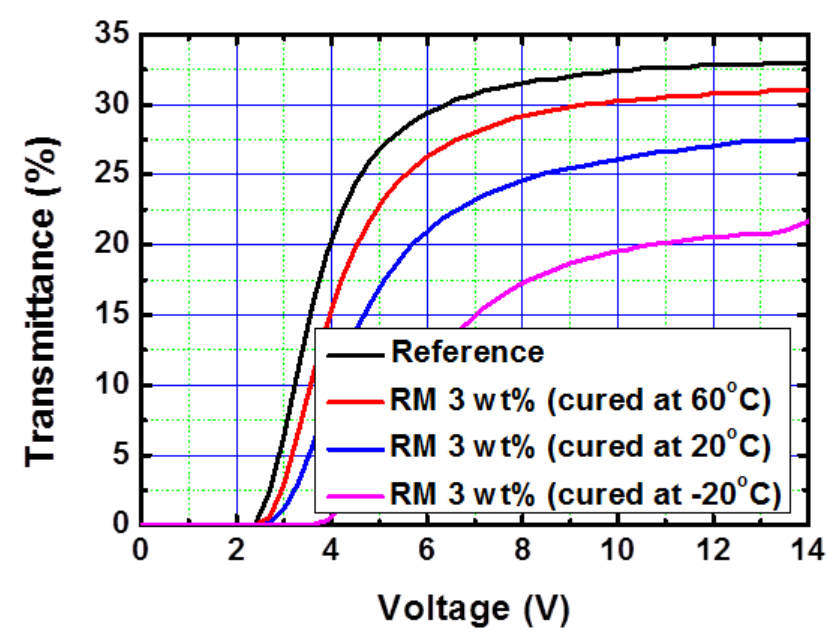

FIG. 7. Measured V-T curves of the VA cells polymernetworked at $60^{\circ} \mathrm{C}, 20^{\circ} \mathrm{C}$, and $-20^{\circ} \mathrm{C}$.

\section{CONCLUSION}

In conclusion, we demonstrated that the response time of a polymer-networked VA cell can be reduced by curing the polymer structure at a low temperature. The turn-off time of a VA cell at room temperature was reduced by $54 \%$ when the polymer structure was cured at $-20^{\circ} \mathrm{C}$. When the operating temperature of the device was $-20^{\circ} \mathrm{C}$ the turn-off time of the cell fabricated by curing the polymer structure at $-20^{\circ} \mathrm{C}$ was decreased by $60 \%$. Our experimental results showed that low-temperature curing of the polymer structure was effective in accelerating the response time. We investigated the reason for the reduction in the turn-off time with lowering curing temperature by using a mathematical model and observing SEM images. We also confirmed that low-temperature curing was more effective in reducing the response time when an LC device is operated at a low temperature.

\section{ACKNOWLEDGMENT}

This work was supported by the National Research Foundation of Korea (NRF) grant funded by the Korea government (MSIP) (No. 2014R1A2A1A01004943).

\section{REFERENCES}

1. S. Nagata, E. Takeda, Y. Nanno, T. Kawaguchi, Y. Mino, A. Otsuka, and S. Ishihara, "Capacitively coupled driving of TFT-LCD," in Proc. SID International Symposium (Baltimore Convention Center, USA, May 1989), pp. 242-245.

2. P. Bos, "Fast-switching liquid-crystal effects for displays," Inf. Disp. 23, 20-25 (2007).

3. S.-M. Jung, J.-U. Park, S.-C. Lee, W.-S. Kim, M.-S. Yang, I.-B. Kang, and I.-J. Chung, "A novel polarizer glassestype 3D displays with an active retarder," in Proc. SID International Symposium (Henry B. Gonzalez Convention Center, USA, June 2009), pp. 348-351.

4. H. K. Shin, J. H. Lee, J.-W. Kim, T.-H. Yoon, and J. C. Kim, "Fast polarization switching panel with high brightness and contrast ratio for three-dimensional display," Appl. Phys. Lett. 98, 063505 (2011).

5. L. Rao, S. Gauza, and S.-T. Wu, "Low temperature effects on the response time of liquid crystal displays," Appl. Phys. Lett. 94, 071112 (2009).

6. M. F. Schiekel and K. Fahrenschon, "Deformation of nematic liquid crystals with vertical orientation in electrical fields," Appl. Phys. Lett. 19, 391-393 (1971).

7. C. Z. van Doorn, "Dynamic behavior of twisted nematic liquid crystal layers in switched fields," J. Appl. Phys. 46, 3738-3745 (1975).

8. M. Oh-e and K. Kondo, "Electro-optical characteristics and switching behavior of the in-plane switching mode," Appl. Phys. Lett. 67, 3895-3897 (1995).

9. K.-H. Kim, E.-Y. Jeon, B. W. Park, S.-W. Choi, D. H. 
Song, H. Kim, K.-C. Shin, H. S. Kim, and T.-H. Yoon, "High-transmittance multi-domain vertical alignment liquid crystal device with protrusion structure," J. Opt. Soc. Korea 16, 166-169 (2012).

10. J.-W. Kim, T.-H. Choi, and T.-H. Yoon, "Design of an electrode structure for the elimination of the off-axis gamma shift in a multi-domain vertical alignment liquid crystal cell," J. Inf. Disp. 15, 19-23 (2014).

11. J.-K. Song, K.-E. Lee, H.-S. Chang, S.-M. Hong, M.-B. Jun, B.-Y. Park, S.-S. Seomun, K.-H. Kim, and S.-S. Kim, "DCCII: Novel method for fast response time in PVA mode," in Proc. SID International Symposium (Washington State Convention and Trade Center, USA, May 2004), pp. 1344-1347.

12. P. J. M. Vanbrabant, N. Dessaud, and J. F. Stromer, "Temperature influence on the dynamics of vertically aligned liquid crystal displays,” Appl. Phys. Lett. 92, 091101 (2008).

13. C. Y. Xiang, J. X. Guo, X. W. Sun, X. J. Yin, and G. J. Qi, "A fast response, three-electrode liquid crystal device," Jpn. J. Appl. Phys. 42, L763-L765 (2003).

14. C. Y. Xiang, X. W. Sun, and X. Y. Yin, "The electrooptic properties of a vertically aligned fast response liquid crystal display with three-electrode driving," J. Phys. D: Appl. Phys. 37, 994-997 (2004).

15. J. L. West, G. Zhang, A. Glushchenko, and Y. Reznikov, "Fast birefringent mode stressed liquid crystal," Appl. Phys. Lett. 86, 031111 (2005).

16. J. S. Gwag, J. C. Kim, and T.-H. Yoon, "Electrically tilted liquid crystal display mode for high speed operation," Jpn. J. Appl. Phys. 45, 7047-7049 (2006).

17. C. Y. Huang, R. X. Fung, Y. G. Lin, and C. T. Hsieh, "Fast switching of polymer-stabilized liquid crystal pi cells," Appl. Phys. Lett. 90, 171918 (2007).

18. J. I. Baek, K.-H. Kim, J. C. Kim, T.-H. Yoon, H. S. Woo, S. T. Shin, and J. H. Souk, "Fast switching of vertical alignment liquid crystal cells with liquid crystalline polymer networks," Jpn. J. Appl. Phys. 48, 056507 (2009).

19. J.-I. Baek, K.-H. Kim, J. C. Kim, T.-H. Yoon, H. S. Woo, S. T. Shin, and J. H. Souk, "Fast in-plane switching of a liquid crystal cell triggered by a vertical electric field," Jpn. J. Appl. Phys. 48, 104505 (2009).

20. D. H. Song, J.-W. Kim, K.-H. Kim, S. J. Rho, H. Lee, H. Kim, and T.-H. Yoon, "Ultrafast switching of randomlyaligned nematic liquid crystals," Opt. Express 20, 1165911664 (2012).

21. B.-H. Yu, D. H. Song, K. H. Kim, B. W. Park, S.-W. Choi, S. I. Park, S. G. Kang, J. H. Yoon, B. K. Kim, and T.-H. Yoon, "Formation of polymer networks for fast in-plane switching of liquid crystals at low temperatures," Jpn. J. Appl. Phys. 52, 094102 (2013).

22. B. W. Park, J.-W. Kim, S.-W. Oh, J.-W. Huh, and T.-H. Yoon, "Fast switching of a vertically-aligned liquid crystal cell by forming polymer networks at a low temperature," in Proc. SID International Symposium (San Diego Convention Center, USA, June 2014), pp. 1473-1475.

23. S. G. Kim, S. M. Kim, Y. S. Kim, H. K. Lee, S. H. Lee, G.-D. Lee, J.-J. Lyu, and K. H. Kim, "Stabilization of the liquid crystal director in the patterned vertical alignment mode through formation of pretilt angle by reactive mesogen,” Appl. Phys. Lett. 90, 261910 (2007).

24. Y.-J. Lee, Y.-K. Kim, S. I. Jo, J. S. Gwag, C.-J. Yu, and J.-H. Kim, "Surface-controlled patterned vertical alignment mode with reactive mesogen," Opt. Express 17, 1029810303 (2009).

25. F. Du and S.-T. Wu, "Curing temperature effects on liquid crystal gels," Appl. Phys. Lett. 83, 1310-1312 (2003).

26. D.-K. Yang, Y. Cui, H. Nemati, X. Zhou, and A. Moheghi, "Modeling aligning effect of polymer network in polymer stabilized nematic liquid crystals," J. Appl. Phys. 114, 243515 (2013). 